commonly ( 79 per cent.) the macular arteries are offsets from the temporal branches of the central artery of the retina, but that in some cases (18 per cent.) they enter the fandus independently by an opening or openings in the optic disc near its temporal margin. Such marginal arteries are commonly called "cilio-retinal,' and the recent anatomical researches of Elschnig, ${ }^{3}$ who states their frequency at 7 per cent., go to prove that thes always arise, directly or indirectly, from the circle of short ciliary arteries which surrounds the optic nerve.

When there is considered the great functional importance of the papillo-macular region and the infrequency of occurrence of cilio-retinal arteries it would seem not at all onlikely that in such cases there is present a supplemental arterial supply of retinal origin, ill developed, bat capable of some extension when the necessity arises. If this be so, then in the present case the small branches of the central retinal artery have been sufficient to maintain the nutrition of all the area of retina affected, except the macula itself and a small strip extending downwards and outwards, till the re-establishment of the circulation in the ressel which had been temporarily occluded. The well-marked atrophy of the temporal side of the optic nerve shows that part to have been entirely dependent for nutrition on the cilio-retinal artery.

There will be noticed in the previous and subsequent history of the present case the frequent occurrence of attacks of transitory blindness of the right eye. Mauthner, ${ }^{4}$ who had the opportunity of examining a patient while suffering from such an attack, found retinal ischrmia, and he explains the occurrence as being due to the temporary detention of a large embolus at the mouth of the central retinal artery, too large to enter, and soon carried on to enter a larger branch of the ophthalmic artery. Such an explanation seems readily applicable to this case, and all the more so that during the period of circulatory calm incident to hosmital residence and treatment no such attacks manifested themselves. Further, it seems quite reasonable to suggest that the occlusion of the common macular artery was caused by the engagement at its origin in a ciliary artery of a large embolns which by the end of eight days was carried on to canse, it may be, embolism of a ressel freely supplied with anastomosis, and therefore giving rise to no gross symptoms.

To recapitulate, there occurred embolism of the common macular or cilio-retinal artery, the embolus being canght at its point of origin. Thus occlusion lasted eight days, during which time the nutrition of part of the retina involved was maintained by small branches of the central retinal artery and by the end of which time the embolus was carried farther into the ciliary circulation.

Glasgow.

\section{REPORT ON "HENPUYE" IN THE GOLD COAST COLONY.}

BY ALBERT J. CHALMERS, M.D. Vict., F.R.C.S. ENG., ASSISTANT COLONIAL SURGEON, ACCRA.

HENPUYE, or dog nose, is a disease frequently met with in the Gold Coast Colony and in certain portions of its Hinterland. The hideous deformity of the face which it causes is very striking to anyone who bas lived in this part of West Africa. It is also known on the Freach Ivory Coast runder the name of "gounda" or "anakhre," but "henpuye" is the native name (Appolonian) for the disease on the Gold Coast. The peculiur nature of the disease and the fact that, as far as I could find, very little was known as to its nature led me to make the inquiries which are now embodied in this report. I regret very much that I am unable to refer to original papers on the subject or to be certain that. I have the full literature, but my excuse is that libraries do not exist in West Africa. The only references which $I$ have met with are those mentioned in Dr. Patrick Manson's work on " Tropical

3 Loc. cit.

4 Archiv für Augenheilkunde, Band xv., S. 28

1 Published by the prrmission of his Kxcellency Sir Frederick Fodgson, Governor of the Gold Coast Colony.
Diseases" (płge 594), and they are those of (1) Professor Alexander Macalister (Royal Irish Academy, 1882), (2) Surgeon J. J. Lamprey A.M.S., (Brit. Med. Jour., vol. ii., 1887), (3) Dr. Henry Strachan (Brit. Med. Jour,, vol. i., 1894), and (4) Dr. Maclaud (Archives de Médecine Navale, 1895). It is by the kind permission of the Governor of this colony, Sir Frederick Hodgson, K.O.M.G., that I am allowed to publish this report. I am mach indebted to Captain Armitage for his kindness in giving me information with regard to the different places in which he has noticed this disease in his travels, for drawing my attention to notes of the late $\mathrm{Mr}$. Ferguson on the presence of the disease in Akim and $\mathrm{Kwahu}$, and for making a painting of an advanced case of the disease ; also to $\mathrm{Dr}$. Henderson, the chief medic al officer of the colony for many kind suggestion; and, lastly, to $\mathrm{Mr}$. Crowther, draughtsman in the Pablic Works Department, for supplying me with a map of the icolony and its Hinterland. The description of the disease will be divided into the following headings: (1) the General Description of the Disease; (2) the Description of Cases of the Disease; (3) the Treatment; (4) the Morbid Anatomy; (5) the Etiology; and (6) the Geographical Distribution.

The General Description of the Disease.

Henpuye starts in a native of West Africa during or soon after an attack of yaws in which there is a bistory of the nasal mucous membrane being attacked as a small bony swelling symmetrically placed on either side of the nose. This swelling, which is generally oval with the long axis directed downwards and outwards, is attached to the nasal bones, the nasal process of the superior maxilla and also to the superior maxilla in the more advanced cases. It is produced by the deposition of new bone under the periosteum on the external aspect of these bones and grows slowly in all directions. It in no way affects the mouth or the orbital or nasal cavities in any case which I have seen and the nasal ducts are quite unaffected. Rarely the growth is asymmetrical, being situated only on one side of the nose. Pain in

\section{FIG. 1.}

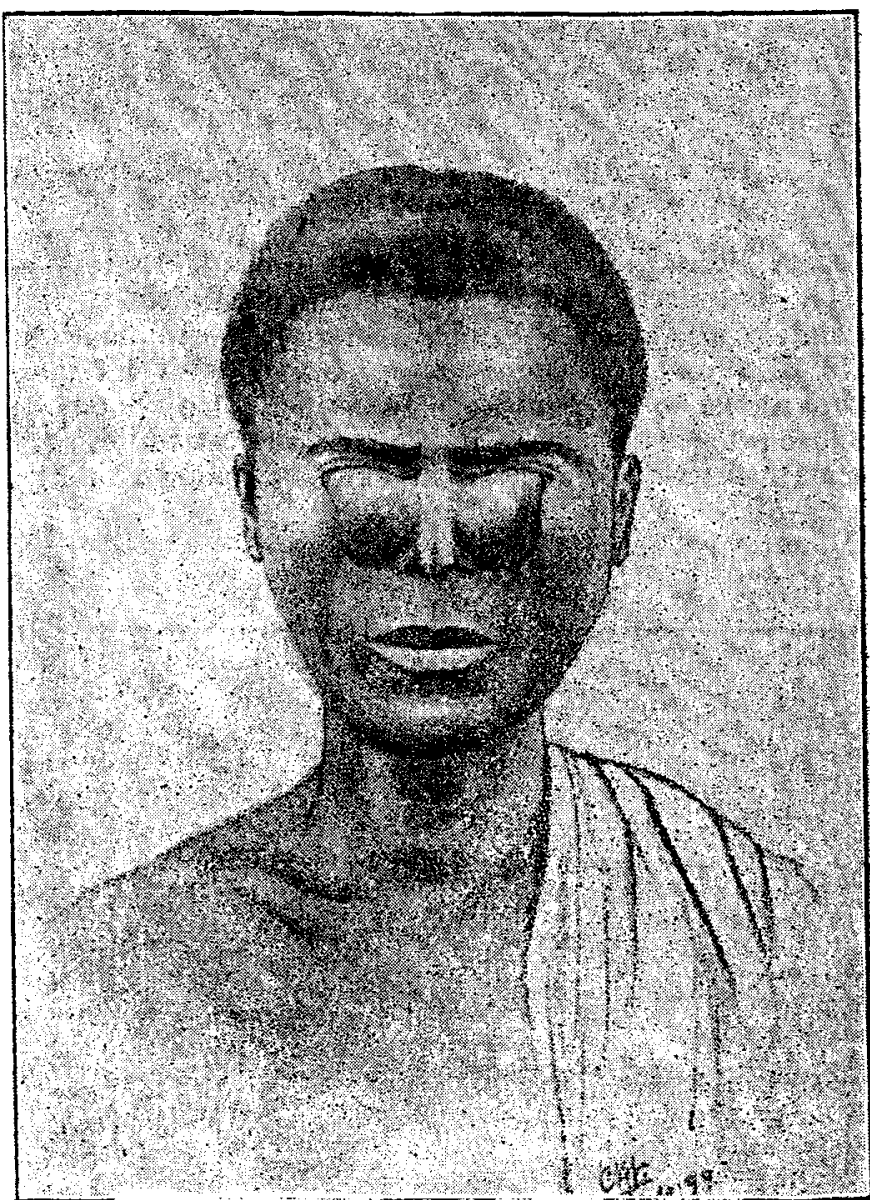

Full-face illustration of a typical advancel case.

the nose with the presence of a sore in that organ are the symptoms complained of at the commencement of the disease; later headache is sometimes felt and pain in the swelling during wet weather. As the growth becomes larger it seriously interferes with the sight by growing up in front of the ejes and even hiding them, bat I have never $s$ en it cause destruction of the eyeball (see Fig. 1). In 
manj cases the patient has to bend his head downwards in order to be able to see over the tops of the swellings. The skin over the tumour is normal and is freely moveable. The course of the disease is that the swellings may cease to grow at any period of their existence or may continue to grow for years-that is to say, they may remain quite small or may grow to be large lumps, in the latter case giving rise to the deformity and the interference with the sight, but $I$ am anacquainted with any case in which they break down or alcerate. Finally, the disease is much more common, in my experience, in men than in women.

\section{Description of Cases.}

The following cases will be described : (1) slightly developed cases; (2) moderately developed cases; (3) an atranced case ; and (4) an asymmetrical case.

Slightly developed cases.-CASE 1.-The patient, a boy of about 17 years of age, said that about seven years ago he noticed two small lumps on the nose which began after yaws in which there was a sore in the nose. They increased slightly in size, but soon ceased to grow and have been in their present condition for some years. He never felt any discomfort or pain in them. The two lumps had their long axes directed downwards and outwards, the measurements being half an inch by a quarter of an inch. They were attached to the nasal bones just above the cartilages and the nasal process of the superior maxilla and were firm, smooth, bony tumours. The skin over them was quite normal and they did not in any way project into the nasal carity or affect the line of vision, being too small for the latter purpose. There was very little deformity and no treatment was necessary. In this case the lumps soon ceased to grow and caused little or no deformity.

CASE 2.-A small Grunshi girl from Kumassi, about seven years of age, who had had yaws some time previously, felt pain in the nose a few months ago and noticed a small swelling on each side of the cose, and this gradually increased in size till it reached its present condition. Her mother was most anxious to have it removed on account of the deformity (see Fig. 2).

FIG. 2.

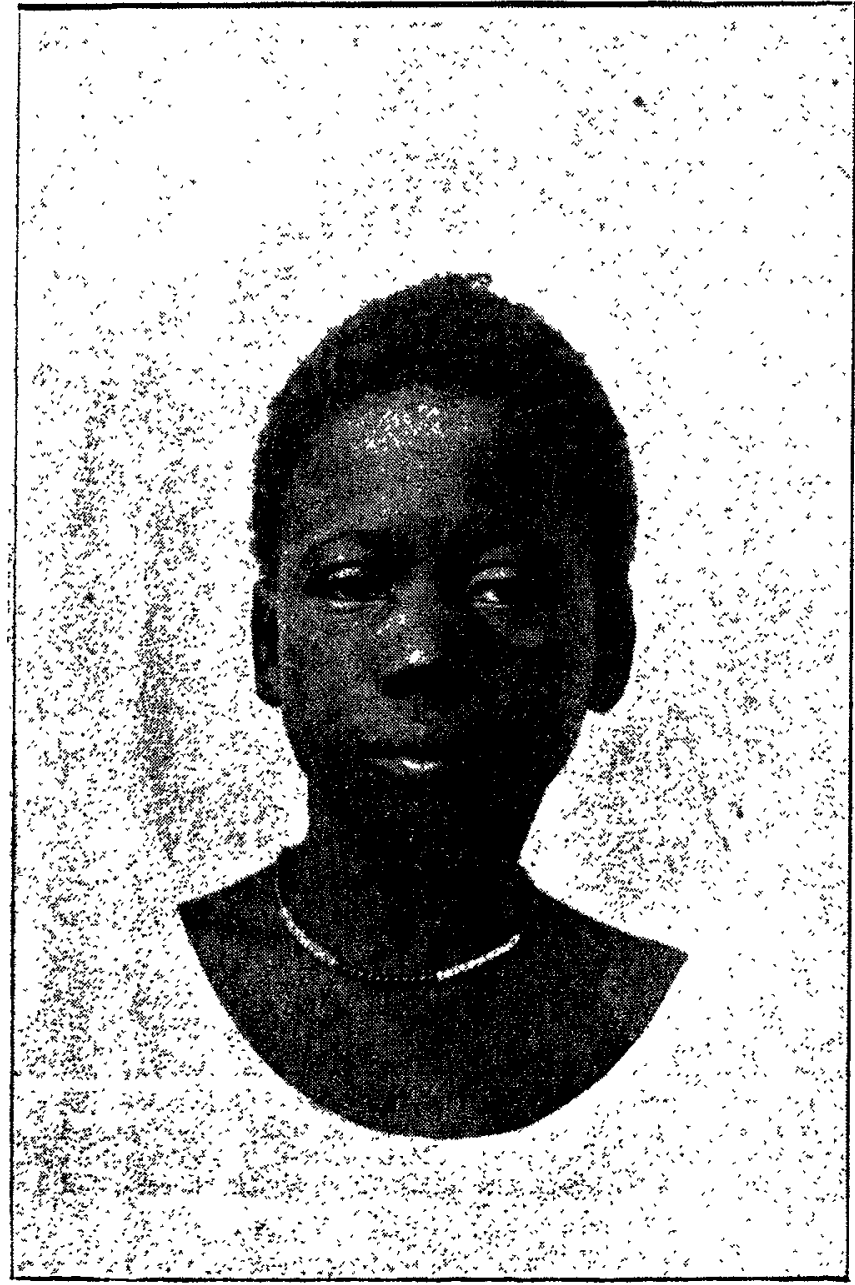

Representation of a slightly developed case (Case 2).

On inspection there was found to be an oval $s$ relling on each side of the nose attached to the nasal bunes and the nasal process of the superior maxilla. The long axis of the swelling was directed downwards and outwards - an inch in length and half an inch in breadth. The nasal cartilages were not affected and the interior of the nose was normal. The orbital cavity, the mouth, and the nasal ducts were quite unaffected. The skin over the swelling was normal and freely moveable. The patient felt no pain in the tumour and she had never had any headacbe. The growths were removed by operation. It was very difficult to obtain definite history as to the time when this patient had had yaws and as to the time when the growth appeared, but as far as I could make out the yaws were well developed when the swelling was first noticed.

Moderately developed cases.-CASE 3.-A young man, a Ga native, who had had yaws about seven years ago, felt pain in the nose and got a person to look into the nose, who said that there were yaw spots on the mucosa and later a small swelling on each side of that organ was noticed. These small swellings grew slowly to their present size and the patient said that they were still increasing. He complained of frontal beadache and of slight pain in the swellings in wet weather. On inspection (Figs. 3 and 4)

FIG. 3.

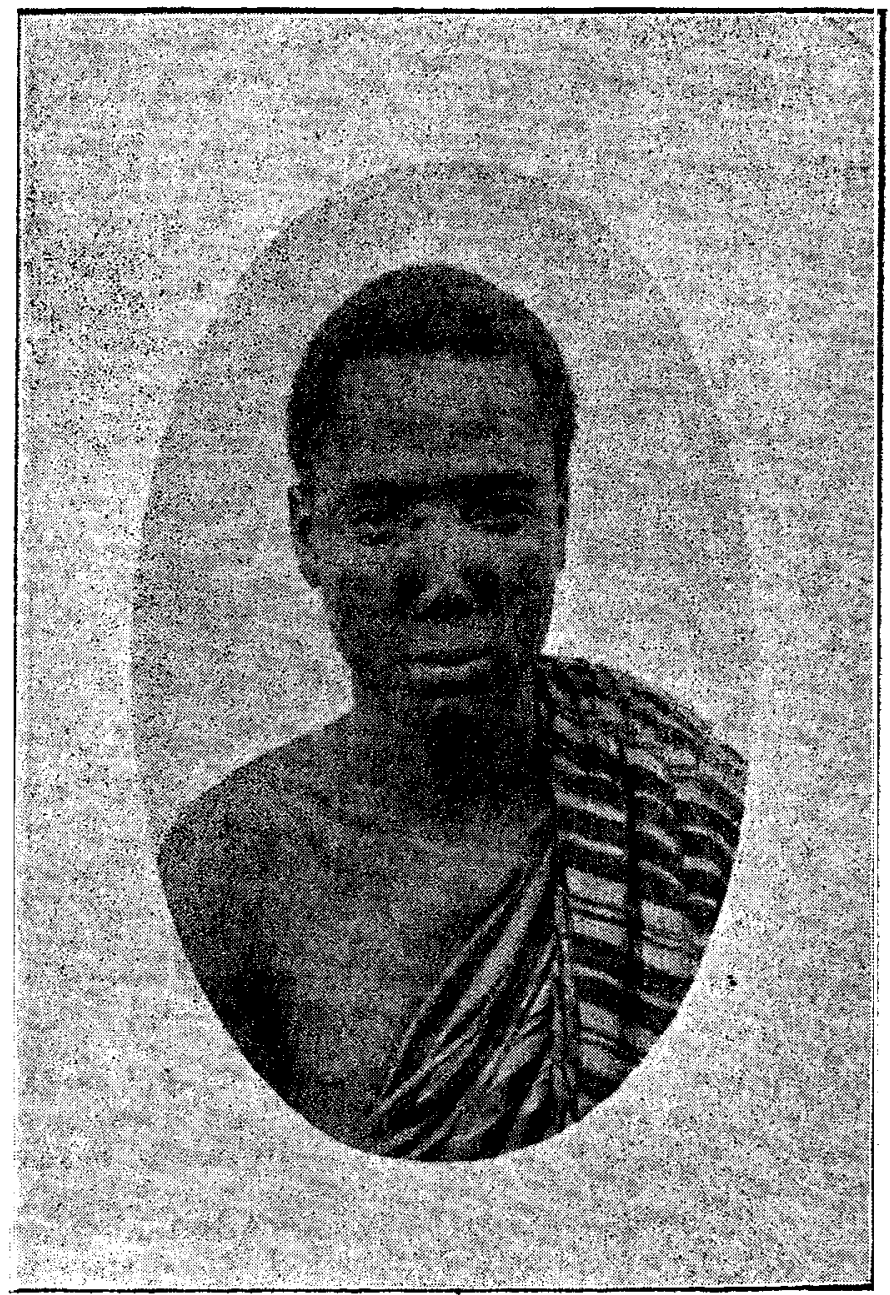

Full-face illustration of the disease as described in Case 3.

two symmetrically placed swellings were seen on each side of the nose, looking some what like small eggs. They were nval in shape, with the long axis directed downwards and outwards. The left measured two inches by two inches and the right three inches by two and a half inches. A profile view showed that they were slightly concave on the side towards the ornit. They did not affect the orbital or nasal cavities, ncr did they project into the mouth or affect the nasal ducts or the cartilages of the nose. They were attached to the nasal bones, the nasal process of the superior maxilla, and to the superior maxilla itself. They were smooth, but on the left side the tumour rose to a central ridge. The skin over the swellings was quite normal and was freely moveable. In order to see clearly the patient often had to bend his head somewhat. The growths were removed by nperation.

CASE 4. - The patient was an Akwapim woman, aged about 20 years. This case was similar to Case 3 , but the swellings, which had started when the patient (who had suffered from yaws) was seven years of age, were rather more rounded. She would not consent to operation.

An advanced sase.-CASE 5.-A man, a native of Appolonia, about 40 years of age, stated that the swellings began with pain in the nose after yaws when he was about six years old. They grew steadily and slowly till eight 
years ago when they stopped, and they have not increased in size since then. On inspection there were two oval swellings situated on each side of the nose, the left measuriog two and a half inches by one inch and the right three-quarters of an inch by half an inch. They projected upwards orer the orbit, the long axis in each case being directed downwards and outwards. They did not project into the mouth, the nose, or the orbit, and the nasal duct was free. They were attached to the nasal bones, the nasal process of the superior maxilla, and to the maxilla itself. The skin over the tumour was normal and

FIG 4.



Representation in profile ofgthe patuell zu lase 0

it was freely moveable. The ratient complained of headache and found that the swellings interfered with his vision considerably, particularly on the left side. He refused to submit to operation.

A $n$ asymmetrical case-CASE 6.-An Ashanti boy, aged six years, from Donkeo Inquanta, had yaws and while suffering therefrom just a year previous to his consulting me the swelling appeared on one side of the nose, and had been growing ever since. There was no sign of any lump on the other side. He was advised to go to Kumassi for operation.

The TrEatment.

I have attempted to reduce these swellings by the adminis. tration of iodide of potassium but have not met with any success. The only treatment appears to be the removal by operation. The method I adopt is as follows. The eyes being protected by a pad over each an incision is made along the long axis of the tumonr and the skin is freed on all sides so that its base is exposed. If the swelling is very small in a child it may be necessary to make a cross cut through the skin as well in order to get sufficient room to work in. The bone being exposed a portion of the swelling can easily be cut a way by bone forceps becanse it is very soft. If large a few nicks with a Hey's saw are found most useful in enabling a large portion of the mass to be removed entire. After as mach has been removed as is possible with the bone forceps more may be got a way by means of the gouge or the gonge forceps or the nibbling forceps. I have experienced difficulty in removing the deeper portions, particularly those close to the orbit. I need hardly say that in the latter the eye has to be carefully guarded from injury. After removal of the bone the wound is well wasbed ont with an antiseptic lotion. The bleeding is slight and is easily controlled by pressure. The wound is closed by a continuous suture and it heals up readily.

\section{The Morbid anatomy.}

I have never had any chance of examining the growth post mortem, but the portions which I bave removed en masse by operation have enabled me to make some investigations. The periosteum strips off readily and under this is a thin shell of compact bone which appears somewhat ridged on the side towards the periosteum. The rest of the tumour consists of cancellous bone. The whole swelling cuts readily with bone forceps and consists of quite soft bone. On making microscopical preparations there were signs of ossification in membrane proceeding under the periosteum and the rest appeared like ordinary wide-meshed cancellous bone. The whole process appeared to be that of a slow "osteoplastic periostitis."

\section{ETIOLOGY.}

Two views on the etiology of this disease have been brought forward up to the present time, as far as I knowviz, that the swellings were of a racial character and that the process was started by the larva of some insect. With regard to the first I have only to mention that the disease is found in Ashantis, Grunshis, Fantees, Ahantas, the Ga people, \&c., \&c., races quite different from one another, to show that this cannot be entertained. As to the second I have never met with evidence which would support the idea that the disease was started by a larva. On the other hand there is always the history of yaws and of the tumour starting during the attack of yaws-i.e., during the period of eruption or soon after Then, again, the patients complain of pain in the nose with, in some cases, distinct history of a sore and sometimes discharge preceding the swelling. This might be due to some irritation or ulceration of the nasal mucous membrane by the yaws. 1 have never had the opportunity of examining any person at this stage of the disease, but in the more developed cases I have examined the nose for marks or signs of old ulceration but have not found them. If, however, the nasal process of the superior maxilla be examined (Fig. 5) a few foramina are

Fig. 5.

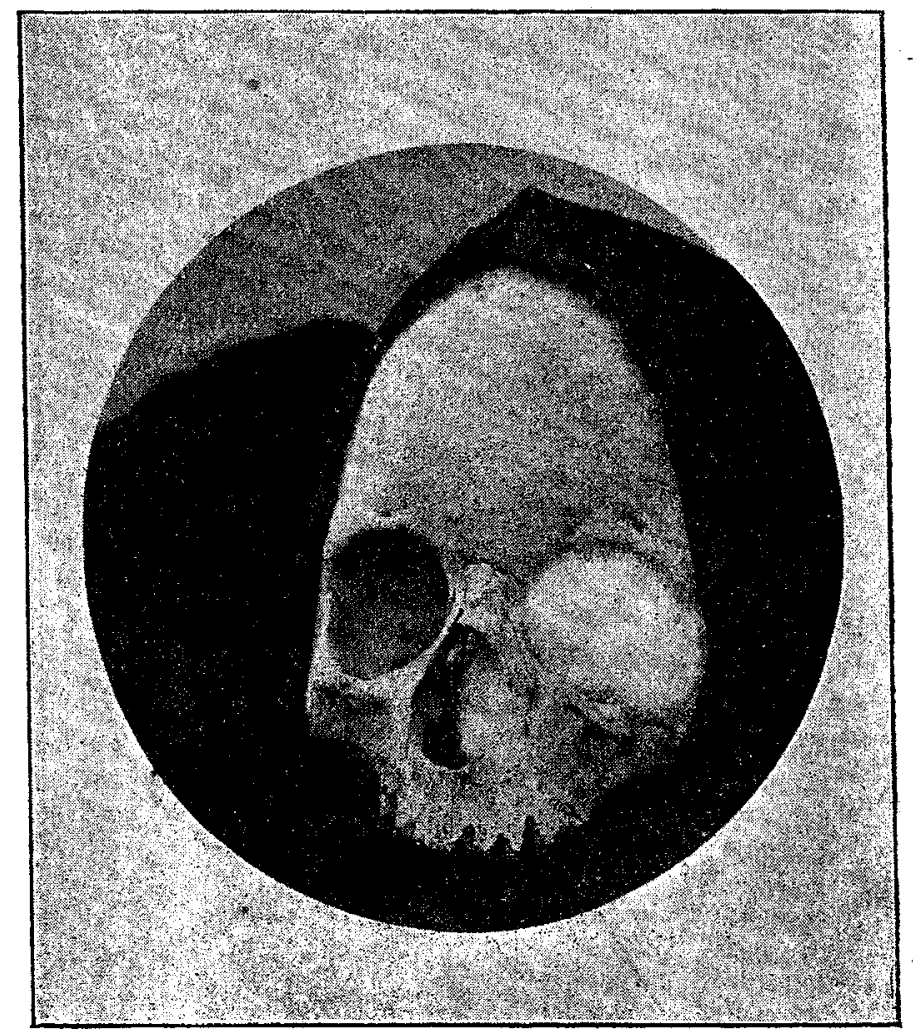

From a photograph of a Mushi skull, to show , he suture ot the nasal process of the superior maxilla, with a hair passed from the nose through one of the channels for vessels, a little of the bone being cut away to show the direction of. the canal.

to be seen, and these are often joined together by a small groove indicating the position of a bygone suture. The foramina are for small blood-vessels which are said to commanicate with those of the mucosa of the nose. The site of these foramina is the situation where henpuye starts and I venture to bring forward the theory that the causation of this peculiar disease is due to an osteoplastic periostitis brought about by the absorption of the poison of yaws from 
the nasal mucous membrane through the small vessels (or Iymphatics) keeping open the foramina which indicate the suture above mentioned.

\section{The Gegogaphical Distribution.}

I am only aware of cases reported from the Gold and Irory Coasts of West Africa and the West Indies. never met with it in Mamprusia, nor have I met any trader coming from Moshi with it, nor have I met with it in Fra Fra, and I can find no one who has seen it in the eastern parts of the colony. But in the following districts it has been noted: Ahanta, Appolonia, Fantee, Accra, Aquapim, Akim, Assin, Sefwhi, Ashanti, Attabubu, Kwahu, Kintampo, Berekum, Gaman, the Neutral Zone, and Wassaw. It is perhaps most common in the Sefwhi, Wassaw, and Appolonia districts which adjoin the French Irory Coast, where cases are also known.

I look upon henpuye as a localised osteoplastic periostitis in the region of the nasal process of the superior maxilla, generally symmetrical, due to yaws and found among the matives of West Africa and the negroes of the West Indies. Accra

\section{THE DIFFERENTIAL DIAGNOSIS OF MONGOLISM AND CRETINISM IN INFANCY.}

\section{By G. A. SUTHERLAND, M.D. EDIN.,}

PHYSICLAN TO PADDINGTON-GREHN CHILDREN'S HOSPITAL; ASSISTANT PHYSICIAN TO THE NORTH-WEST IONDON HOSPITAL.

UNDER the term "cretinoid" have been included various forms of imbecility in infants which until recent years were not clearly differentiated as to their pathology and characteristic features. In practice we find that children of the cretinoid type are either cretins or Mongolian imbeciles. Cretinism, or infantile myxœedema, is a rare affection in this country, but in the medical literature of the past few years, owing to the successful employment of the thyroid gland treatment, many cases have been reported. Morgolism is a form of congenital imbecility which is much more common but to which comparatively little attention has been directed. It is so named from certain facial appearances which at first sight suggest a Chinese origin. The term was introduced by Dr. Langdon-Down in his classification of idiots on an ethnological basis, and although his classification has not been generally accepted the name "Mongolian" has been adopted as happily descriptive. This form of imbecility is well known to those engaged in asylum practice, but it is during the early months of life that diagnosis is called for and treatment must be adopted if those fragile lives are to be prolonged.

Owing to the similarities between these two affections, "cretinism " and "Mongolism," which are at first sight very striking, confusion is apt to arise. In both the physical and mental development is delayed, the vital powers are low, the temperature is subnormal, and sensitiveness to cold is a marked feature. In both occur the following facial alterations-viz, depressed bridge of the nose, small palpebral fissure, and protruding tongue. In both the abdomen is large, an umbilical hernia is often present, and there is a marked tendency to constipation. In both the fontanelle is late in closing and the teeth are late in appearing, are poorly developed, and decay rapidly. In both speech is much delayed and is replaced by peculiar, grunting, animal-like noises, while snoring during sleep is very pronounced. In both there is great muscular debility without any definite paralysis. Hence it may happen that a case of Mongolism is regarded as one of cretinism; thyroid treatment is adopted, and this failing to produce any benefit becomes rather discredited in the eyes of the physician. If, instead of comparing, we contrast a typical case of Mongolism (Fig. 1) with one of cretinism (Fig. 2) we find that the differences are great and should render the distinction easy.
FIG. 1.



A ctse of Mongolian imbecility.

FIG. 2.

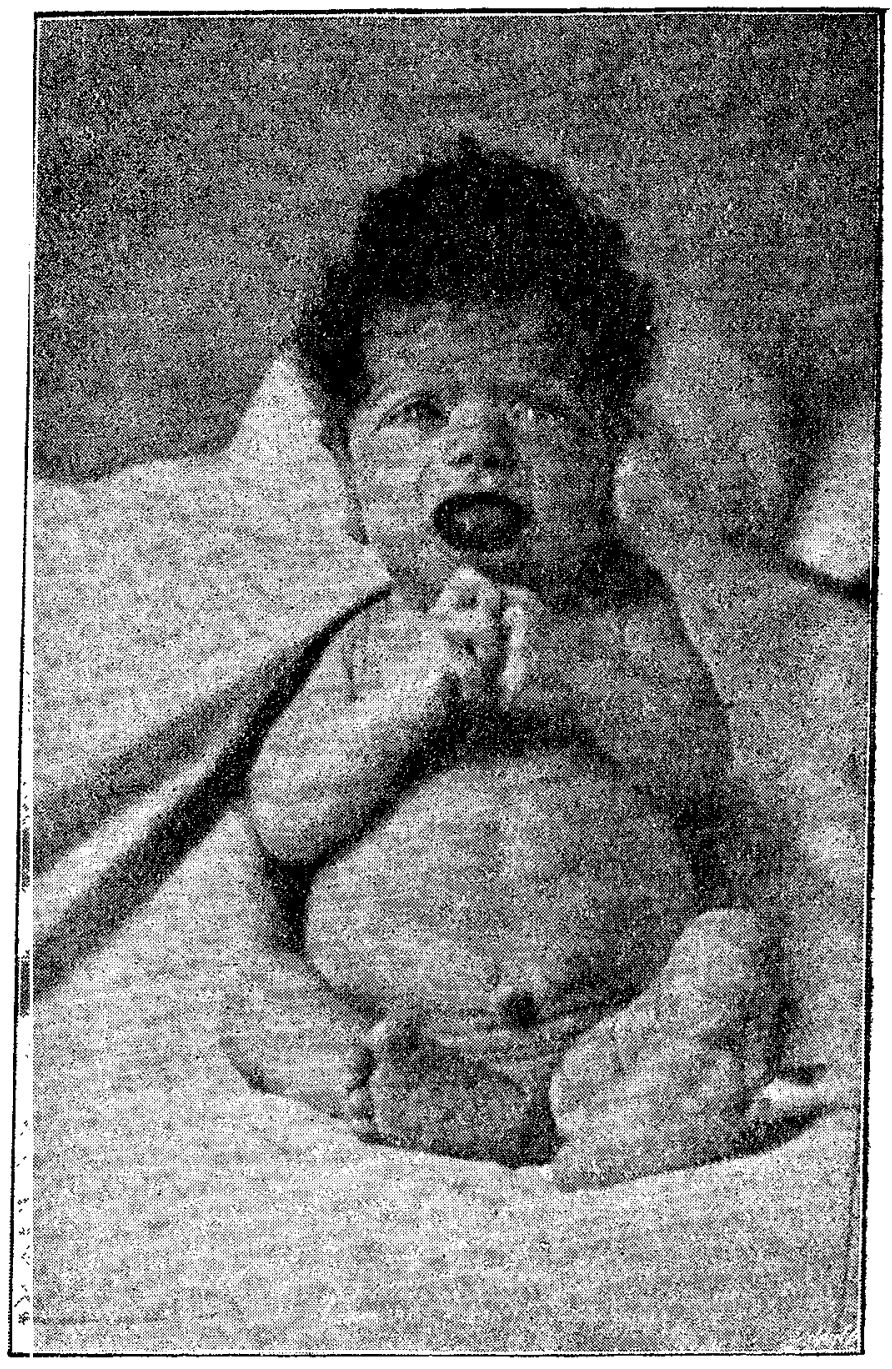

A case of cretiusm. 